\title{
IMPACT OF ABLEIST MICROAGGRESSIONS ON UNIVERSITY STUDENTS WITH SELF-IDENTIFIED DISABILITIES
}

\author{
A Thesis \\ Submitted In Partial Fulfillment of the Requirements \\ for the Degree of \\ Bachelor of Science (Honours) in Psychology \\ University of Regina
}

\author{
by \\ Kayla Lett \\ Regina, Saskatchewan
}

April, 2018 


\begin{abstract}
Ableist microaggressions are brief or covert insults that are targeted towards individuals based on their disability status (Keller \& Galgay, 2010; Sue et al., 2007). Qualitative studies of people with disabilities reveal that anger, embarrassment, and frustration are commonly experienced in relation to ableist microaggressions, suggesting that psychological outcomes could be impacted (Keller \& Galgay, 2010). However, more quantitative studies are required to examine this relationship. Studies of racial microaggressions have found that these experiences are related to poorer academic performance, lower self-esteem, and poorer mental health outcomes (Ikram et al., 2016; Nadal, Wong, Griffin, Davidoff, \& Sriken, 2014; Solorzano, Ceja, \& Yosso, 2000). Institutional betrayal could also be an exacerbating factor on mental health for those who experience racial microaggressions (Gómez, 2015). The current study examined the relationship between ableist microaggressions and academic performance, self-esteem, and mental health outcomes. Canadian university students $(n=111)$ with self-identified disabilities completed a survey that assessed disability-related discrimination, institutional betrayal, academic performance, self-esteem, and mental health. Experiences of discrimination were significantly correlated with greater symptoms of anxiety, depression, and poorer academic self-concept. Institutional betrayal was also significantly correlated with experiences of discrimination, symptoms of anxiety, depression, and poorer academic self-concept. Ableist microaggressions and overt discrimination negatively impact university students and highlight the need for additional psychological and academic supports for students with disabilities on campus.
\end{abstract} Keywords: ableist microaggressions, disability, institutional betrayal 


\section{Acknowledgments}

I would like to express my sincerest gratitude to my supervisor, Dr. Bridget Klest, whose guidance and expertise has cultivated my passion for research. Her invaluable advice, experience, and continued support allowed me to grow as a student and researcher. I am also extremely grateful for the financial support received from Dr. Klest’s mentorship grant, which helped to facilitate this research project. A very special thank you goes out to my co-supervisor, Andreea Tamaian, who answered my countless questions, helped with data analysis, and provided tremendous support with editing. Thank you for sharing your insight, experience, and knowledge with me. I am honoured to have both you and Dr. Klest as my mentors. I would also like to thank the graduate students and volunteers of the Social Context, Health, and Trauma Laboratory for providing me with valuable feedback and supportive comments throughout this journey. Finally, I would like to acknowledge the participants of this research project. Thank you for taking the time to share your experiences with us. 
Impact of Ableist Microaggressions on University Students with Self-Identified Disabilities

Disability is a complex term that encompasses the functional, environmental, and social limitations that an individual may face due to his or her health status (Grönvik, 2007). While people with disabilities commonly deal with barriers in their daily lives, they also experience discrimination at the individual and institutional levels (Keller \& Galgay, 2010). For example, individuals with disabilities are sometimes avoided during social interactions when other abledbodied individuals are present. Institutional barriers such as the lack of elevators or accessible doorways also constitute discrimination. Interpersonal discrimination can come in a variety of different forms, both obvious and subtle (Keller \& Galgay, 2010). For example, receiving substandard service at a restaurant would be considered overt discrimination (Sue et al., 2007). Covert forms of discrimination include intrusive health questions, such as asking how an individual acquired his or her disability (Keller \& Galgay, 2010). Research studies are beginning to explore the relationship between disability-related discrimination and its impact on the wellbeing of individuals with disabilities.

\section{Disability in Canada}

In 2012, an estimated 3.8 million Canadians over the age of 15 years were living with a disability that impacted their daily activities (Statistics Canada, 2015). Disabilities involving pain, flexibility, and mobility were reported as the most common, with many of these conditions co-occurring (Statistics Canada, 2015). Although individuals with disabilities are less likely to complete a post-secondary education program, $14 \%$ of 25 - to 64 -year olds with disabilities have completed at least one university certificate, diploma, or degree (Statistics Canada, 2015). To facilitate equal access to education and promote success, universities are required by law to make their services accessible to all people (Mullins \& Preyde, 2013). Despite the availability of 
additional support (e.g., accessibility centres), several barriers to accessing university services persist (Cox \& Klas, 1996; Mullins \& Preyde, 2013). In a study of Canadian universities, Hill (1992) found eight disability-related issues that required improvement, including the accessibility of the campus facilities and the attitudes of faculty and staff. The willingness of professors to allow accommodations for course assignments (e.g., recording lectures and extending deadlines) was noted as a frequent issue. These problems constitute discrimination against individuals with disabilities that hinder their integration and success within a postsecondary institution.

\section{Microaggressions}

Microaggressions refer to subtle verbal, behavioural, or environmental slights and insults that communicate a hostile or derogatory message based on an individual's social status (Sue et al., 2007). Perpetrators are often unaware that they have committed a microaggression, as these acts can be either intentional or unintentional (Sue et al., 2007). Microaggressions can be committed based on age, gender, race, sexual orientation, or disability status (Derthick, 2015; Keller \& Galgay, 2010; Nadal et al., 2011; Solorzano, Ceja, \& Yosso, 2000; Zimmerman, 2017). Racial microaggressions have been studied the most, particularly with respect to the classification of these experiences and their impact on individual targets (Gómez, 2015; Hughey, Rees, Goss, Rosino, \& Lesser, 2017; Sue et al., 2007; Wong, Derthick, David, Saw, \& Okazaki, 2014).

Racial microaggressions. Sue et al. (2007) identified three specific types of microaggressions that can be perpetrated against racial minorities: microassaults, microinsults, and microinvalidations. Microassaults are explicit verbal or nonverbal attacks intended to hurt the target through name-calling, avoidant behaviour, or discriminatory actions. The conscious 
and deliberate nature of these microaggressions is a defining characteristic of the microassault. This type of microaggression is most likely to be expressed in private situations, where the perpetrator feels safe to express his or her personal biases. In contrast, microinsults are communications that convey a rude or insensitive message to the target. Microinsults can be verbal or non-verbal, and are unknown to the perpetrator in most instances. An example of a verbal microinsult would be asking an individual how they attained their employment, which suggests that they are not qualified for the position. Non-verbal microinsults could include avoiding eye contact or failing to acknowledge the presence of a racial minority individual. Microinvalidations describe communications that ignore or nullify the thoughts, feelings, or experiences of an individual. Complimenting the English language ability of an ethnic minority individual is a common racial microinvalidation. Statements such as, "I don’t see colour,” also constitute microinvalidations because they negate the unique cultural experiences of the target. Not only are these microaggressions embarrassing and upsetting to experience, but they also have significant impact on the mental health and overall functioning of the individual (Ikram et al., 2016; Nadal, Wong, Griffin, Davidoff, \& Sriken, 2014; Solorzano et al., 2000).

Experiences of racial microaggressions have been associated with lower self-esteem, depressive symptoms, and poorer academic performance (Ikram et al., 2016; Nadal, Wong, Griffin, Davidoff, \& Sriken, 2014; Solorzano et al., 2000). In a cross-sectional study of first and second generation ethnic minorities living in Europe, Ikram and colleagues (2016) examined the relationship between perceived ethnic discrimination, ethnic identity, and depressive symptoms. They found that experiences of racial microaggressions were positively correlated with depressive symptoms, suggesting that microaggressions constitute a form of chronic stress that could have a damaging effect on mental health. Nadal and colleagues (2014) found that racial 
microaggressions experienced in an educational environment (i.e., perpetrated by students or faculty members) contributed to lower self-esteem. Solorzano and colleagues (2000) studied the impact of racial microaggressions and an unsupportive campus on academic performance. Using a qualitative, focus-group design, they explored the experiences of racial minority students at predominantly White universities in the United States. Students expressed that dealing with microaggressive experiences daily led them to become frustrated, discouraged, and exhausted, which left them with little energy to strive academically. Others felt intimidated if they were the only minority student in their classrooms, which produced a barrier to participation in class activities. Racial microaggressions caused several students to drop out of university or change institutions due to their negative experiences. These findings suggest that the university plays an integral role in the perpetration and response to discrimination against minority students.

Institutional betrayal. When a wrongdoing is perpetrated by an institution on an individual dependent on that institution, that individual may experience feelings of institutional betrayal (Smith \& Freyd, 2013). Smith and Freyd (2013) studied institutional betrayal within the context of campus sexual assault and found that survivors experienced greater psychological harm when an institution was unsupportive or failed to respond appropriately to the trauma. Similar effects of institutional betrayal have been found in other systems, such as the medical system and the military (Monteith, Bahraini, Matarazzo, Soberay, \& Smith, 2016; Tamaian \& Klest, 2017). Gómez (2015) suggested that institutional betrayal may exacerbate the impact of racial microaggressions on mental health. For example, an individual of racial minority may seek out mental health treatment, but they may experience microaggressions while receiving the treatment. As a result, the mental health institution potentially caused harm to the individual, creating additional barriers to receiving future treatment. Similar instances of institutional 
betrayal could also occur within universities where microaggressions are perpetrated and not prevented or adequately responded to at an institutional level.

Ableist microaggressions. Ableism refers to negative attitudes and prejudice targeted towards an individual based on his or her disability status (Fierros, 2006). This prejudice is maintained through individual biases that favour able-bodied people and discriminatory structures or practices within institutions, including universities (Beratan, 2006; Kattari, 2015). Inaccessible public facilities, inequitable employment practices, and educational policies that focus on student segregation are common examples of ableism in society (Beratan, 2006; Loja, Costa, Hughes, \& Menezes, 2013; Shier, Graham, \& Jones, 2009). When ableism is combined with subtle or brief acts of discrimination, ableist microaggressions are formed (Kattari, 2017). An example of an ableist microaggression would be providing unsolicited encouragement to an individual based on his or her disability status (Kattari, 2017). Perpetrators of ableist microaggressions are often unaware of the detrimental impact of their behaviour and usually believe that their actions are helpful (Keller \& Galgay, 2010). Compared to racial microaggressions, ableist microaggressions are understood to a lesser extent and lack quantitative data to explore their impact on overall functioning.

Investigations of ableist microaggressions have utilized qualitative designs to gather detailed information regarding the experiences of individuals with disabilities (Bell, 2013; Kattari, 2017; Keller \& Galgay, 2010). In a focus group study, Keller and Galgay (2010) collected data from 12 participants with disabilities. Research team members that identified with a disability facilitated the focus group interviews in a semi-structured format, creating an open atmosphere in which individuals felt comfortable to share their experiences. The results of the study highlighted eight specific domains of ableist microaggressions that are commonly 
experienced: denial of identity, denial of privacy, helplessness, secondary gain, spread effect, patronization, second-class citizenship, and desexualization. Denial of identity occurs when an individual's disability is overemphasized compared to other salient attributes (e.g., personality traits, specialized skills). Privacy can also be denied, which often occurs when strangers ask individuals with disabilities about their health status and previous history. Helplessness can be experienced by both the target and the perpetrator of the microaggression. Individuals with disabilities are often provided with help, even when they do not ask for it. This suggests that people with disabilities are not capable of living without assistance, which could potentially damage their self-esteem.

Conversely, perpetrators feel helpless when encountering a person with a disability, because disabilities are beyond personal control (Keller \& Galgay, 2010). To cope with their own state of helplessness, Keller and Galgay (2010) explain that perpetrators intervene when it is inappropriate or unnecessary to do so. The domain of secondary gain describes perpetrators who interact or serve individuals with disabilities to receive extrinsic or intrinsic rewards. Within this domain, microaggressions are viewed as a source of social exploitation. The spread effect refers to the ascription of ability or disability in other areas of an individual's overall functioning, based on the presence of his or her disability. For example, a perpetrator may assume that someone with a visual impairment is incapable of speaking. Patronization describes situations where individuals with disabilities are treated as inferior or as if they were children. They are also treated as second-class citizens, or deemed burdensome by those who are able-bodied. This creates an additional institutional barrier, as public facilities may avoid making accessibility accommodations based on financial constraints or other limitations (e.g., historical protection). Desexualization was another common theme from the focus groups. Perpetrators view 
individuals with disabilities as incapable of sexual activity or unworthy of romantic

relationships. Experiencing microaggressions from these eight domains on a regular basis was connected to feelings of embarrassment, anger, and frustration. This suggests that distressing psychological symptoms could be associated with ableist microaggressions. However, further quantitative investigation is required to delineate this relationship.

\section{Hypotheses}

The current study aimed to quantitatively assess disability-related discrimination experienced by Canadian university students and examine the potential impacts that these experiences have on academic performance, self-esteem, and mental health outcomes. Based on studies of racial microaggressions, we hypothesized that experiences of disability-related discrimination would be correlated with poorer academic performance, lower self-esteem, and negative mental health outcomes (i.e., increased symptoms of depression and anxiety). Furthermore, we hypothesized that experiences of IB related to disability would also be correlated with poorer academic performance, self-esteem, and mental health.

\section{Method}

\section{Participants}

University accessibility centres across Canada were contacted to distribute information about the study to students enrolled at their institutions. The recruitment of participants was facilitated via email listservs, posters, and social media advertisements. Inclusion criteria required participants to be registered as an undergraduate or graduate student at a Canadian university and to self-identify with a physical, cognitive, or psychological disability. 


\section{Procedure}

An online survey using the Qualtrics platform was used for data collection. Interested participants accessed the survey via an anonymous link. Informed consent was obtained prior to the start of the survey. The survey was approximately 20 minutes in length. Participants were asked to respond to the measures outlined in the following section. Upon completion of the online survey, participants were given the choice to receive a \$10 online gift certificate to Amazon which were distributed via email.

\section{Measures}

Demographics. Participants were asked to provide their age, gender, ethnicity, and university location. Level of university education, academic major, and accessibility centre enrollment status were also assessed. Participants classified their disability as "physical”, “cognitive”, “psychological”, or “other”.

Grade point average (GPA) and grade dissatisfaction. GPA refers to the cumulative mean grade obtained by a student for their coursework in an educational program. Participants were asked to provide their GPA as a baseline measurement of academic performance. Depending on the academic institution, GPA may be expressed as a percentage or as a score on a four-point or five-point scale. GPA conversion tables were obtained from a graduate admissions office at the University of Regina to facilitate the standardization of this variable. Since GPA does not consider the student's personal expectations, a single-item grade dissatisfaction measure was included. Participants were asked to rate their grade dissatisfaction on a five-point Likert scale from “extremely unsatisfied” to "extremely satisfied”. This measure provided insight into the participant's level of approval for their university academic performance. 
Ableist Microaggressions Scale (AMS-65; Kattari, 2017). The AMS-65 is a self-report scale used to assess the experiences of ableist microaggressions. It was developed using qualitative interviews with disability stakeholders (i.e., individuals with disabilities, researchers, and advocates) to identify common microaggressive experiences, followed by exploratory and confirmatory factor analyses. The scale contains 65 items related to specific microaggressive interactions and participants were asked to indicate whether this type of microaggression has happened to them. For example, one of the items states, "I was labelled as inspirational for doing daily activities based on my disability status.” The AMS-65 has displayed good construct validity and as well as high reliability with a Cronbach’s alpha of .98 (Kattari, 2017).

Everyday Discrimination Scale (EDS; Williams, Yu, Jackson, \& Anderson, 1997). The EDS measures chronic or routine acts of overt discrimination, such as being treated with less respect and courtesy than other people based on social status. This scale contains nine items of discriminatory acts and participants were asked to indicate the frequency of occurrence for each on a 6-point Likert scale from 0 (never) to 5 (almost everyday). The EDS has displayed good construct validity, convergent validity, and reliability with a Cronbach’s alpha of .88 (Krieger, Smith, Naishadham, Hartman, \& Barbaeu, 2005; Taylor, Kamarck, \& Shiffman, 2004).

\section{Institutional Betrayal and Support Questionnaire (IBSQ; Smith \& Freyd, 2016).}

The IBSQ was based on the original 10-item Institutional Betrayal Questionnaire (IBQ; Smith \& Freyd, 2013), which was designed to assess an institution's response to a wrongdoing or traumatic experience that occurred within the institution. The IBSQ contains 23 items regarding institutional betrayal (i.e., the institution's inaction or inappropriate response), as well as items regarding instances of the institution supporting an individual through his or her negative experience (Smith \& Freyd, 2016). The instructions and items of the IBSQ have been adapted for 
this study to ask participants about their university’s response to events related to disability discrimination. For example, one item from the IBSQ asks participants if their university played a role by "not doing enough to prevent this type of experience.” Participants were prompted to indicate whether each institutional response has happened to them, by selecting “yes”, “no”, or “not applicable”. The "no” and "not applicable” responses were aggregated prior to conducting statistical analyses.

Academic Self-Concept Scale (ASCS; Reynolds, 1988). The ASCS was developed to assess the non-cognitive aspects of academic performance (e.g., confidence, planning, and expectations) which are not captured adequately using GPA alone. This 40-item scale asks participants about their feelings toward specific academic experiences and skills, such as study habits, exam performance, and peer comparisons. For example, one item states, "I feel I do not study enough before a test.” Participants were asked to indicate if they agreed or disagreed with each statement on a 4-point Likert scale from 1 (strongly disagree) to 4 (strongly agree). The ASCS has demonstrated good construct validity, adequate reliability, and internal consistency (Reynolds, 1988).

Single-Item Self-Esteem Scale (SISE; Robins, Hendin, \& Trzesniewski, 2001). The SISE was designed to assess self-esteem using a short, face-valid item. Developed as an alternative to the 10-item Rosenberg Self-Esteem Scale (RSE; Rosenberg, 1965), the single item states, “I have high self-esteem.” Participants indicated their response to this item on a 5-point Likert scale from 1 (not very true of me) to 5 (very true of me). The minimal response requirement for this measure was desirable for the study due to survey fatigue that can be experienced with lengthy questionnaires. Correlations with the RSE suggest that the SISE has 
good construct, convergent, and discriminant validity, despite its minimal response requirement (Robins et al., 2001).

\section{General Anxiety Disorder 7-Item Scale (GAD-7; Spitzer, Kroenke, Williams, \&}

Löwe, 2006). The GAD-7 was developed as a brief clinical measure of generalized anxiety disorder that can be used in both clinical and research settings. Participants were asked to indicate how often they have been bothered by problems such as, “feeling nervous, anxious, or on edge” and "being so restless that it’s hard to sit still” in the past two weeks. Frequency was rated on a 4-point Likert scale from 0 (not at all sure) to 3 (nearly every day). Next, participants were asked to rate how difficult these problems have made working, taking care of home responsibilities, and interacting with others on a 4-point Likert scale from 0 (not difficult at all) to 3 (extremely difficult). This scale has demonstrated good reliability, in addition to criterion, construct, and procedural validity (Spitzer et al., 2006). Internal consistency is also high, with a Cronbach’s alpha of .92 (Spitzer et al., 2006).

Patient Health Questionnaire-9 (PHQ-9; Kroenke, Spitzer, \& Williams, 2001). The PHQ-9 is a self-report assessment of depressive symptoms. Participants were asked to indicate how often they have been bothered by problems such as, "feeling down, depressed, or hopeless" and "feeling tired or having little energy" in the past two weeks. A 4-point Likert scale was used to rate the frequency, from 0 (not at all) to 3 (nearly every day). The severity of these problems was assessed by the participant indicating how difficult these problems have made working, taking care of home duties, and getting along with others on a 4-point Likert scale from 0 (not difficult at all) to 3 (extremely difficult). The internal reliability of the PHQ-9 is high, with a Cronbach’s alpha of .89 (Kroenke et al., 2001). Construct, criterion, and external validity were also achieved with this measure (Kroenke et al., 2001). 


\section{Results}

\section{Demographics}

A total of 111 participants from universities across Canada completed the survey: 69.4\% from Alberta (University of Lethbridge), 18.9\% from Prince Edward Island (University of Prince Edward Island), 5.4\% from Quebec (McGill University), and 4.5\% from Saskatchewan (University of Regina). The participants’ages ranged from 18 to 47, with a mean age of 22.8 years and standard deviation of 5.02 years. Approximately $73.0 \%$ of the sample identified as female, 19.8\% identified as male, and six participants (5.4\%) identified as “other”. For ethnicity, most of the participants identified as "White” (82.0\%), while 6.3\% identified as “Asian”, 1.8\% as “First Nations,” 1.8\% as “Black”, 1.8\% as “Hispanic”, 1.8\% as “Middle Eastern”, and 2.7\% as "Multiracial”. In order to be eligible for the study, participants had to self-identify as having a disability. A total of $40.5 \%$ of the sample reported having a psychological disability, $35.1 \%$ a cognitive disability, $18.0 \%$ a physical disability, and $4.5 \%$ indicated they have multiple disabilities. All participants were enrolled in a degree-based program, with $89.2 \%$ registered in an undergraduate program and 9.0\% registered in a graduate program. Most participants indicated that they were registered at a student accessibility centre on campus (93.7\%), while 4.5\% indicated that they were not registered.

\section{Mean Scores}

Means and standard deviations were calculated for all variables, summarized in table 1 below. Higher scores on the ableist microaggressions measure indicate that many different types of microaggressions were experienced. In contrast, higher scores on the overt discrimination measure indicate increasing type and frequency of discriminatory events. For the institutional betrayal and support variables, higher scores indicate greater experiences of each type of 
institutional response. Higher GPA scores represent increased achievement in graded university coursework, whereas higher scores on the academic self-concept measure indicate increased engagement in productive academic behaviours (e.g., studying for exams and completing assignments). Higher scores on the grade dissatisfaction and self-esteem measures indicate increased grade dissatisfaction and lower self-esteem, respectively. For the anxiety and depression variables, higher scores reflect greater experiences of symptoms as well as increased frequency of the symptoms.

Table 1: Means and standard deviations of all variables

\begin{tabular}{lllll}
\hline Variable & $\begin{array}{l}\text { Minimum } \\
\text { Score }\end{array}$ & $\begin{array}{l}\text { Maximum } \\
\text { Score }\end{array}$ & Mean & $\begin{array}{l}\text { Standard } \\
\text { deviation }\end{array}$ \\
\hline $\begin{array}{l}\text { Ableist } \\
\text { microaggressions }\end{array}$ & 6 & 59 & 30.81 & 14.18 \\
$\begin{array}{l}\text { Overt discrimination } \\
\text { Institutional betrayal }\end{array}$ & 9 & 54 & 43.66 & 9.62 \\
Institutional support & 0 & 14 & 2.42 & 3.34 \\
GPA & 0 & 100 & 3.69 & 2.51 \\
$\begin{array}{l}\text { Academic self- } \\
\text { concept }\end{array}$ & 62 & 131 & 100.09 & 16.28 \\
$\begin{array}{l}\text { Grade } \\
\text { dissatisfaction }\end{array}$ & 1 & 5 & 2.75 & 1.33 \\
$\begin{array}{l}\text { Self-esteem } \\
\begin{array}{l}\text { Symptoms of } \\
\text { anxiety }\end{array}\end{array}$ & 1 & 5 & 2.46 & 1.17 \\
$\begin{array}{l}\text { Symptoms of } \\
\text { depression }\end{array}$ & 0 & 21 & 12.06 & 6.37 \\
\hline
\end{tabular}

\section{Pearson Correlations}

Pearson correlations were conducted to explore the strength of the relationships between: experiences of disability-related discrimination (i.e., ableist microaggressions and overt 
discrimination), academic performance (i.e., GPA, academic self-concept, and grade dissatisfaction), institutional betrayal, institutional support, anxiety, depression, and self-esteem. Small, medium, and large effect sizes for Pearson correlation correspond to $r=0.1,0.3$, and 0.5 respectively (Cohen, 1992). Prior to conducting the correlations, the IBSQ items were analyzed for response patterns. For the individual IBSQ items, “not applicable” responses accounted for $15.3 \%$ to $68.5 \%$ of responses. In total, “not applicable” responses accounted for $37.5 \%$ of responses to institutional support items and $47.5 \%$ of responses to institutional betrayal items. Due to the high proportion of "not applicable” responses, "no” and “not applicable” responses were aggregated for the institutional betrayal and support variables. The correlation matrix for all study variables is presented in table 2 below.

Table 2: Correlations between disability-related discrimination and outcome variables

\begin{tabular}{|c|c|c|c|c|c|c|c|c|c|c|}
\hline Variable & GPA & $\begin{array}{c}\text { Grade } \\
\text { dissatisfaction }\end{array}$ & $\begin{array}{c}\text { Academic } \\
\text { self- } \\
\text { concept }\end{array}$ & $\begin{array}{c}\text { Overt } \\
\text { discrimination }\end{array}$ & $\begin{array}{c}\text { Ableist } \\
\text { microaggressions }\end{array}$ & $\begin{array}{c}\text { Anxiety } \\
\text { symptoms }\end{array}$ & $\begin{array}{c}\text { Depression } \\
\text { symptoms }\end{array}$ & $\begin{array}{c}\text { Self- } \\
\text { esteem }\end{array}$ & $\begin{array}{c}\text { Institutional } \\
\text { betrayal }\end{array}$ & $\begin{array}{c}\text { Institutional } \\
\text { support }\end{array}$ \\
\hline GPA & 1 & & & & . & & & & & \\
\hline $\begin{array}{l}\text { Grade } \\
\text { dissatisfaction }\end{array}$ & $-.607 * * *$ & 1 & & & . & & & & & \\
\hline $\begin{array}{l}\text { Academic self- } \\
\text { concept }\end{array}$ & $.421^{* * *}$ & $-.569 * * *$ & 1 & & & & & & & \\
\hline $\begin{array}{l}\text { Overt } \\
\text { discrimination }\end{array}$ & -.090 & $.259 * *$ & $-.375^{* * *}$ & 1 & & & & & & \\
\hline $\begin{array}{l}\text { Ableist } \\
\text { microaggressions }\end{array}$ & .076 & .083 & $-.280 * *$ & $.683^{* * *}$ & 1 & & & & & \\
\hline $\begin{array}{l}\text { Anxiety } \\
\text { symptoms }\end{array}$ & .112 & .108 & $-.454^{* * *}$ & $.415^{* * *}$ & $.469^{* * *}$ & 1 & & & & \\
\hline $\begin{array}{l}\text { Depression } \\
\text { symptoms }\end{array}$ & .033 & $.203^{*}$ & $-.591 * * *$ & $.402 * * *$ & $.383^{* * *}$ & $.655^{* * *}$ & 1 & & & \\
\hline Self-esteem & .045 & $-.280 * *$ & $.571^{* * *}$ & $-.274 * *$ & -.196 & $-.465 * * *$ & $-.588 * * *$ & 1 & & \\
\hline $\begin{array}{l}\text { Institutional } \\
\text { betrayal }\end{array}$ & .002 & .008 & $-.312^{* *}$ & $.342 * *$ & $.421 * *$ & $.304^{* *}$ & $.321^{* *}$ & -.143 & 1 & \\
\hline $\begin{array}{l}\text { Institutional } \\
\text { support }\end{array}$ & -.054 & -.055 & .039 & .094 & .061 & -.029 & -.011 & .001 & -.082 & 1 \\
\hline
\end{tabular}

notes: ${ }^{* * *} p<.001,{ }^{* *} p<.01,{ }^{*} p<.05$ 
Experiences of overt discrimination were correlated with poorer academic self-concept ( $r$ $=-.375, p<.001)$, increased grade dissatisfaction $(r=.259, p<.01)$, lower self-esteem $(r=-$ $.274, p<.01)$, greater symptoms of anxiety $(r=.415, p<.001)$, and greater symptoms of depression $(r=.402, p<.001)$. A medium effect was also found between experiences of overt discrimination and institutional betrayal $(r=-.342, p<.01)$. No statistically significant relationship was found between overt discrimination and GPA.

Experiences of ableist microaggressions were correlated with increased symptoms of anxiety $(r=.469, p<.001)$ and depression $(r=.383, p<.001)$, as well as poorer academic selfconcept $(r=-.280, p<.01)$. In addition, there was a large effect between experiences of overt discrimination and ableist microaggressions $(r=.683, p<.001)$. GPA and grade dissatisfaction were not significantly correlated with ableist microaggressions. A correlation between ableist microaggressions and poorer self-esteem approached significance $(r=-.196, p=.056)$.

Lastly, institutional betrayal was correlated with increased experiences of ableist microaggressions $(r=.421, p<.01)$, overt discrimination $(r=.342, p<.01)$, poorer academic self-concept ( $r=-.312, p<.01)$, greater symptoms of anxiety $(r=.304, p<.01)$, and greater symptoms of depression $(r=.321, p<.01)$. In contrast, institutional betrayal was not significantly correlated with GPA, grade dissatisfaction, or self-esteem. Institutional support was not significantly correlated with any of the variables.

\section{Discussion}

The present study predicted that experiences of ableist microaggressions and overt discrimination would be correlated with poorer academic performance, mental health status, and self-esteem. This hypothesis was mostly supported. Participants who reported greater experiences of microaggressions and overt discrimination had increased symptoms of anxiety 
and depression, as well as poorer academic self-concept. Ikram and colleagues (2016) found that racial microaggressions contributed to poorer mental health, which is consistent with the present study. Lower self-esteem was related to greater experiences of overt discrimination. A correlation between ableist microaggressions and lower self-esteem approached significance. These findings are similar to the Nadal and colleagues (2014) study which found that racial microaggressions contributed to lower self-esteem.

The measures of GPA, grade dissatisfaction, and self-esteem did not have a consistent relationship with disability-related discrimination or institutional betrayal. Greater experiences of overt discrimination were correlated with increased grade dissatisfaction and lower self-esteem, but no significant relationship was found with GPA. Similarly, GPA, grade dissatisfaction, and self-esteem did not display significant correlations with ableist microaggressions or institutional betrayal. However, poorer academic self-concept was significantly correlated with both experiences of overt discrimination, ableist microaggressions, and institutional betrayal. GPA, grade dissatisfaction, and self-esteem were assessed using single-item measures. In contrast, the ASCS scale assessed academic performance using a series of items related to academic behaviours. Since university students with disabilities are prone to socially desirable responding, it is possible that the single-item measures did not provide an accurate reflection of these variables (De Cesarei \& Baldaro, 2015). University students may be more protective of their self-image due to their disability status, and may attempt to normalize their individual characteristics (Crocker \& Major, 1989). Therefore, the measures of GPA, grade dissatisfaction, and self-esteem could have been inflated for this sample.

The present study also hypothesized that institutional betrayal related to discriminatory experiences would be correlated with poorer academic performance, mental health status, and 
self-esteem. When responding to the IBSQ, many participants chose the "not applicable” option which lead to non-significant correlations with all variables when kept separate from the "no" responses. Since many of the IBSQ items focus on the reporting of a negative experience, it is possible that the "not applicable" response was selected frequently due to the lack of resources for reporting discrimination on campus (Borland \& James, 1999). Alternatively, it is possible that the participants did not feel comfortable disclosing their institutional experience. Overall, institutional betrayal was significantly correlated with ableist microaggressions, poorer academic self-concept, depression, and anxiety. This suggests that the university institution plays a role in academic and mental health outcomes for students who experience disability-related discrimination. In addition, there were no significant correlations between institutional support and the outcome variables. The large proportion of "not applicable" responses on the support items of the IBSQ suggests that support provided by the university is currently not sufficient to help mitigate negative outcomes created by experiences of discrimination and therefore does not impact the academic and mental health outcomes of students with disabilities (Borland \& James, 1999). It is also possible that the support services are difficult to access, or that the lack of student reporting of discriminatory experiences does not allow the university to endorse support (Borland \& James, 1999). However, a more comprehensive investigation would be required to better understand the factors influencing institutional support of university students with disabilities.

There are several important limitations to this study that should be considered. Firstly, the sample was relatively small and contained students from only four Canadian universities. In addition, the sample contained mostly White participants and was restricted to those who could read English. Therefore, the results of this study may not generalize to other Canadian university 
students, or to students of non-dominant ethnicity. Ethnicity is an important factor to consider since it could influence the experience of discrimination. Secondly, multiple types of selfidentified disabilities were combined in this study. It is possible that disability type affects the experience of discrimination and consequently alters its impact on academic performance and mental health status. For example, most physical disabilities are more visible compared to psychological or cognitive disabilities. Thus, it is possible that individuals with visible and invisible disabilities experience different types of discrimination, which differentially impact their academic and mental health outcomes. Thirdly, it is possible that some participants were not able to successfully complete the survey due to their disability status (De Cesarei \& Baldaro, 2015). Although accessibility accommodations were offered throughout the recruitment process, some individuals may have been prevented from participating due to the requirement of understanding and responding to questions in this study.

The present study provides a foundation for further quantitative research regarding ableist microaggressions. Future quantitative studies should focus on specific types of disability to provide a greater understanding of the factors that influence discrimination (e.g., severity of disability, visibility of disability status). It would also be valuable to obtain a sample that proportionally represents all ethnicities within the population, which would increase the generalizability of the results. An experimental design could be implemented to better understand types of microaggressions and their immediate impact on the target, as well as the causal link between discrimination, institutional betrayal, and mental health outcomes. Overall, the findings of this study illustrate the various detrimental impacts that disability-related discrimination has on university students. As a result, academic institutions should strive to ensure campus environments are accessible to all students and that the campus community is 
educated on disability-related discrimination. Furthermore, it is imperative that university institutions play an active role in combating discrimination at all levels. This could include the revision and creation of policies to ensure inclusivity, providing advocacy for students experiencing discrimination, and facilitating mediation to resolve conflicts surrounding discriminatory events. These actions would help to improve trust in the institution, as it is important that students feel that their institution will protect and serve them when discriminatory events occur. Receiving a supportive response from the institution could help to reduce negative effects associated with these events (Foynes \& Freyd, 2013). Providing additional academic and psychological support (e.g., counselling services, tutoring, discrimination reporting system) to students with disabilities could also lessen the impact of discrimination and improve outcomes. 


\section{References}

Bell, A. K. (2013). Nothing about us without us: A qualitative investigation of the experiences of being a target of ableist microaggressions. Available from ProQuest Dissertations \& Theses Global. Retrieved from https://login.libproxy.uregina.ca:8443/login?url=https://search-proquestcom.libproxy.uregina.ca:8443/docview/1536397558?accountid=13480

Beratan, G. D. (2006). Institutionalizing inequity: Ableism, racism and IDEA 2004. Disability Studies Quarterly, 26(2), 3. Retrieved from http://dsq-sds.org/article/view/682

Borland, J., \& James, S. (1999). The learning experience of students with disabilities in higher education. A case study of a UK university. Disability \& Society, 14(1), 85-101.

Cohen, J. (1992). A power primer. Psychological bulletin, 112(1), 155.

Cox, D. H., \& Klas, L. D. (1996). Students with learning disabilities in Canadian colleges and universities: A primer for service provision. Journal of Learning Disabilities, 29(1), 9397. doi:10.1177/002221949602900111

Crocker, J., \& Major, B. (1989). Social stigma and self-esteem: The self-protective properties of stigma. Psychological review, 96(4), 608.

De Cesarei, A., \& Baldaro, B. (2015). Doing online research involving university students with disabilities: Methodological issues. Computers in Human Behavior, 53, 374-380.

Derthick, A. O. (2015). The sexist mess: Development and initial validation of the sexist microaggressions experiences and stress scale and the relationship of sexist microaggressions to women's mental health (Doctoral dissertation, University of Alaska Anchorage). Retrieved from 
https://search.proquest.com/openview/28559a11ea039d100a1e8d8d59e71228/1?pqorigsite $=$ gscholar $\&$ cbl=18750\&diss=y

Fierros, E. G. (2006). One size does not fit all: A response to institutionalizing inequity. Disability Studies Quarterly, 26(2), 11. Retrieved from http://dsqsds.org/article/view/683

Foynes, M. M., \& Freyd, J. J. (2013). An exploratory study evaluating responses to the disclosure of stressful life experiences as they occurred in real time. Psychological Trauma: Theory, Research, Practice, and Policy, 5(3), 295.

Gómez, J. M. (2015). Microaggressions and the enduring mental health disparity: Black Americans at risk for institutional betrayal. Journal of Black Psychology, 41(2), 121-143. doi:10.1177/0095798413514608

Grönvik, L. (2007). Definitions of disability in social sciences: Methodological perspectives (Doctoral dissertation, Acta Universitatis Upsaliensis). Retrieved from https:/uu.diva-portal.org/smash/get/diva2:170048/FULLTEXT01.pdf

Hill, J. L. (1992). Accessibility: Students with disabilities in universities in Canada. Canadian Journal of Higher Education, 22(1), 48-83. Retrieved from http://journals.sfu.ca/cjhe/index.php/cjhe/article/view/183122/183098

Hughey, M. W., Rees, J., Goss, D. R., Rosino, M. L., \& Lesser, E. (2017). Making everyday microaggressions: An exploratory experimental vignette study on the presence and power of racial microaggressions. Sociological Inquiry, 87(2), 303-336. doi:10.1111/soin.12167

Ikram, U. Z., Snijder, M. B., de Wit, M. A., Schene, A. H., Stronks, K., \& Kunst, A. E. (2016). Perceived ethnic discrimination and depressive symptoms: The buffering effects of ethnic 
identity, religion and ethnic social network. Social Psychiatry and Psychiatric Epidemiology, 51(5), 679-688. doi:10.1007/s00127-016-1186-7

Kattari, S. K. (2015). Examining ableism in higher education through social dominance theory and social learning theory. Innovative Higher Education, 40(5), 375-386. doi:10.1007/s10755-015-9320-0

Kattari, S. (2017). Development of the ableist microaggression scale and assessing the relationship of ableist microaggressions with the mental health of disabled adults. Electronic Theses and Dissertations. Retrieved from http://digitalcommons.du.edu/etd/1283

Keller, R. M., \& Galgay, C. E. (2010). Microaggressive experiences of people with disabilities. Microaggressions and marginality: Manifestation, dynamics, and impact, 241-268. Hoboken, N.J: John Wiley \& Sons, Inc.

Krieger, N., Smith, K., Naishadham, D., Hartman, C., \& Barbeau, E. M. (2005). Experiences of discrimination: Validity and reliability of a self-report measure for population health research on racism and health. Social Science \& Medicine, 61(7), 1576-1596. doi:10.1016/j.socscimed.2005.03.006

Kroenke, K., Spitzer, R. L., \& Williams, J. B. W. (2001). The PHQ-9: Validity of a brief depression severity measure. Journal of General Internal Medicine, 16(9), 606-613. doi:10.1046/j.1525-1497.2001.016009606.x

Loja, E., Costa, M. E., Hughes, B., \& Menezes, I. (2013). Disability, embodiment and ableism: Stories of resistance. Disability \& Society, 28(2), 190-203. doi:10.1080/09687599.2012.705057 
Monteith, L. L., Bahraini, N. H., Matarazzo, B. B., Soberay, K. A., \& Smith, C. P. (2016). Perceptions of institutional betrayal predict suicidal self-directed violence among veterans exposed to military sexual trauma. Journal of Clinical Psychology, 72(7), 743755. doi:10.1002/jclp.22292

Mullins, L., \& Preyde, M. (2013). The lived experience of students with an invisible disability at a Canadian university. Disability \& Society, 28(2), 147-160. doi:10.1080/09687599.2012.752127

Nadal, K. L., Issa, M. A., Leon, J., Meterko, V., Wideman, M., \& Wong, Y. (2011). Sexual orientation microaggressions: “Death by a thousand cuts” for lesbian, gay, and bisexual youth. Journal of LGBT Youth, 8(3), 234-259. doi:10.1080/19361653.2011.584204

Nadal, K. L., Wong, Y., Griffin, K. E., Davidoff, K., \& Sriken, J. (2014). The adverse impact of racial microaggressions on college students' self-esteem. Journal of College Student Development, 55(5), 461-474. doi:10.1353/csd.2014.0051

Reynolds, W. M. (1988). Measurement of academic self-concept in college students. Journal of Personality Assessment, 52(2), 223-240. doi:10.1207/s15327752jpa5202_4

Robins, R. W., Hendin, H. M., \& Trzesniewski, K. H. (2001). Measuring global self-esteem: Construct validation of a single-item measure and the Rosenberg Self-Esteem Scale. Personality and Social Psychology Bulletin, 27(2), 151-161. doi:10.1177/0146167201272002

Rosenberg, M. (1965). Society and the adolescent self-image. Princeton, N.J: Princeton University Press. doi:10.1126/science.148.3671.804 
Shier, M., Graham, J. R., \& Jones, M. E. (2009). Barriers to employment as experienced by disabled people: A qualitative analysis in Calgary and Regina, Canada. Disability \& Society, 24(1), 63-75. doi:10.1080/09687590802535485

Smith, C. P., \& Freyd, J. J. (2013). Dangerous safe havens: Institutional betrayal exacerbates sexual trauma. Journal of Traumatic Stress, 26(1), 119-124. doi:10.1002/jts.21778

Smith, C. P. \& Freyd, J. J. (2016, August). Campus sexual violence: Moving from institutional betrayal to institutional courage. In symposium presented at the annual meeting of the American Psychological Association, Denver, CO.

Solorzano, D., Ceja, M., \& Yosso, T. (2000). Critical race theory, racial microaggressions, and campus racial climate: The experiences of African American college students. The Journal of Negro Education, 69(1/2), 60-73. Retrieved from http://www.jstor.org/stable/2696265

Spitzer, R. L., Kroenke, K., Williams, J. B., \& Löwe, B. (2006). A brief measure for assessing generalized anxiety disorder: The GAD-7. Archives of Internal Medicine, 166(10), 10921097. doi:10.1001/archinte.166.10.1092

Statistics Canada. (2015). A profile of persons with disabilities among Canadians aged 15 years or older. Canadian Survey on Disability, 2012. Statistics Canada Catalogue no. 89-654-X. Ottawa. Released November 30, 2015. Retrieved from http://www.statcan.gc.ca/pub/89654-x/89-654-x2015001-eng.htm

Sue, D. W., Capodilupo, C. M., Torino, G. C., Bucceri, J. M., Holder, A., Nadal, K. L., \& Esquilin, M. (2007). Racial microaggressions in everyday life: implications for clinical practice. American Psychologist, 62(4), 271. doi:10.1037/0003-066X.62.4.271 
Tamaian, A., \& Klest, B. (2017). Institutional betrayal in the Canadian medical system: Reliability and validity of a self-report questionnaire. Journal of Aggression, Maltreatment \& Trauma, 18(1), 1-17. doi:10.1080/10926771.2017.1294638

Taylor, T. R., Kamarck, T. W., \& Shiffman, S. (2004). Validation of the Detroit Area Study Discrimination Scale in a community sample of older African American adults: the Pittsburgh healthy heart project. International Journal of Behavioral Medicine, 11(2), 8894. doi:10.1207/s15327558ijbm1102_4

Williams, D. R., Yu, Y., Jackson, J. S., \& Anderson, N. B. (1997). Racial differences in physical and mental health: Socio-economic status, stress and discrimination. Journal of Health Psychology, 2(3), 335-351. doi:10.1177/135910539700200305

Wong, G., Derthick, A. O., David, E. J. R., Saw, A., \& Okazaki, S. (2014). The what, the why, and the how: A review of racial microaggressions research in psychology. Race and Social Problems, 6(2), 181-200. doi:10.1007/s12552-013-9107-9

Zimmerman, L. (2017). An investigation of geriatric microaggressions, relations with depression in later life, and the moderating effect of coping (Doctoral dissertation). Retrieved from ProQuest Dissertations Publishing. (1954685451) 